\title{
TRANSURETHRAL RESECTION OF A URINARY BLADDER MASS IN A HAEMOPHILIAC PATIENT
}

N KABIR, M J KABIR

Department of Urology, Lab Aid Specialized Hospital, Dhaka, Bangladesh,

\section{Case Report}

A 57 year old hypertensive gentleman from Mymensingh presented with the history of hematuria for 2 weeks. He was treated with fresh frozen plasma (FFP), whole blood and Factor VIII concentrates. An USS showed blood and a space occupying lesion (SOL) in the urinary bladder. The repeated USS showed a similar picture. He was given FFP and Factor VIII preoperatively. His Factor VIII concentration was found to be $7.9 \%$ and his Activated Partial Thromboplastin Time (APTT) was 54 seconds (control-38seconds)

Just before the operation 4 vials of Factor VIII each containing 5000 units were given to the patient. The Trans Urethral Recession biopsy was smooth without any complications. Another concentrate of Factor VIII was given after 6 hours.

His post operative urine washout was crystal clear. On the second post operative day the patients urine became high colour and haemorrhagic. The Factor VIII concentrate was continued at 5000 units daily for 5 days. Urine washout was intermittently haemorrhagic for 2 to 3 weeks. Amino caproic acid (Caprolysin) and FFP were also included in the management intermittently. It took almost three weeks for the urine colour to become fully clear.

The histopathology report revealed three pieces of soft tissue, the largest one measuring $0.6 \mathrm{~cm}$ in diameter. The microscopic finding showed that the urinary bladder mucosa lined by urothelium show von Brunn's nest. The sub epithelium is oedematus, congested and infiltrated with acute and chronic inflammatory cells. No granuloma or evidence of malignancy seen.

\section{Discussion:}

Haemophilia is a group of $X$ linked conditions. Elevated rates of HIV and hepatitis $C$ related malignancies in patients with haemophilia has been well documented, however rates of other types of cancers have not been

Correspondences: N. Kabir, Department of Urology, Lab Aid Specialized Hospital, Dhaka, Bangladesh, E-mail: jkabir@bol-online.com well established[1]. With increasing medical facilities and better understanding and treatment of the blood disorders many people now can survive up to normal life expectancy. Like any others, bladder tumor is common among these individuals and their treatment requires special attention. Haemophilia A results from a congenital deficiency of clotting factor VIII and has an incidence of approximately 1 in 5000 live male births[2]. Haemophilia B occurs as a result of factor IX deficiency and has an incidence of 1 in 20000 male births[3]. The availability of clotting factors has rendered surgery in haemophiliacs as safe as for any other normal subjects. However surgeries should be avoided whenever possible. If surgery is required then it should be carried out in a center where multidisciplinary approach is present. The presence of specialist in haematology, orthopedics, dentistery and surgery are of utmost importance. Proper nursing should be available and presence of physiotherapists and social works together with related allied health professionals are of great benefits[4]. The patient should be monitored constantly since bleeding can arise as a late complication. The World federation of hemophilia (WFH) strongly recommends the use of viral inactivated plasma-derived or recombinant concentrates in preference to cryoprecipitate or fresh frozen plasma for the treatment of hemophilia and other inherited bleeding disorders $[5,6]$. In this case factor VIII concentrate was given at 12 hour interval. The adequate dose to increase factor level to 0.5 to $1 \mathrm{U} / \mathrm{ml}$ and to maintain a level of $0.4 / \mathrm{ml}$. The dose can be less in minor procedures. Tranexamic acid may be given alone or together with standard dose of coagulation factor concentrates[7]. Tranexamic acid should not be given to patients with Factor IX deficiency receiving prothrombin complex concentrates, as this will exacerbate the risk of thromboembolism[8]. Thromboembolism is less likely when tranexamic acid is used in combination with rFVIIa to enhance hemostasis[9]. Cryoprecipitate is preferable to FFP and due to its safety and quality[10]. 
In the present case the surgery and post operative management of the patient was successful with judicial use of factor 8, FFP and amino caproic acid.

\section{Conflict of Interest : None Declared}

\section{References:}

1. Dunn AL. Malignancy in patients with haemophilia: a review of the literature. Haemophilia, 2010 May; 16(3):427-36. doi: 10.1111/j.1365-2516. 2009; 02128.x. Epub 2009 Nov 11.

2. Mannucci PM, Tuddenham EG The haemophilliasfrom royal genes to gene therapy. New Eng J Med 344, 1773-9 (2001)

3. Soucie JM, EvattB, Jackson D Occurrence of haemophilia in the United States. The Haemophilia Surveillance system project investigators. Am J Hematol 59, 288-94 (1998)

4. Rizza CR. Inhibitors of fibrinolysis in the treatment of haemophiliaJ Clin Pathol Suppl (R Coll Pathol). 1980; 14: 50-54.

5. Evatt BL, Austin H, Leon G, Ruiz-SáezA, de Bosch N. Haemophilia therapy: assessing the cumulative risk of HIV exposure by cryoprecipitate. Haemophilia 1999;5(5):295-300.
6. Farrugia A. Guide for the assessment of clotting factor concentrates, 2nd ed. Montreal: World Federation of Hemophilia, 2008. Hvas AM, Sorensen $H T$, Norengaard L, et al.

7. Tranexamic acid combined with recombinant factor VIII increases clot resistance to accelerated fibrinolysis in severe hemophilia A. J Thromb Haemost 2007;5(12):2408-14.

8. Luu $\mathrm{H}$, Ewenstein B. FEIBA safety profile in multiple modes of clinical and home-therapy application. Haemophilia 2004 Sep;10 (Suppl 2):10-6.

9. Giangrande PL, Wilde JT, Madan B, et al. Consensus protocol for the use of recombinant activated factor VII in elective orthopaedic surgery in haemophilic patients with inhibitors. Haemophilia 2009;15(2):501-8.

10. Stanworth SJ. The evidence-based use of FFP and cryoprecipitate for abnormalities of coagulation tests and clinical coagulopathy. Hematology Am Soc Hematol Educ Program 2007:179-86.

\section{Abbreviations:}

FFP : Fresh Frozen Plasma

WFH : World Federation of Haemophilia 